International Journal of Advanced Chemistry, $8(1)(2020) 147-154$
International Journal of Advanced Chemistry
SPC
Website: www.sciencepubco.com/index.php/IJAC
Research paper

\title{
Adsorption of Methyl Orange Dye onto Raw Maize Cob and Maize Cob Activated Carbon: Isotherms and Thermodynamic Studies
}

\author{
Safiyya Ibrahim Abubakar ${ }^{1 *}$, Muhammad Adamu Ibrahim ${ }^{1}$, Muhammad Bashir Ibrahim ${ }^{1}$ \\ ${ }^{1}$ Department of Pure and Industrial Chemistry, Bayero University, P.M.B. 3011, Kano -Nigeria \\ *Corresponding author E-mail: safiyyaiaramadan@gmail.com
}

\begin{abstract}
This study was aimed to evaluate the adsorption of Methyl orange (MO) onto raw maize cob (RMC) and maize cob activated carbon (MCAC) from aqueous solution using batch adsorption studies. The produced adsorbents were characterized by Scanning electron microscope (SEM), and Fourier transform infrared spectroscopy (FTIR). The influence of contact time, dosage, concentration, temperature, and $\mathrm{pH}$ were investigated as well as Isotherm and Thermodynamic studies. Effect of contact time showed that Methyl orange adsorption were found to reach equilibrium within 125 and 110 minutes with optimum percentage removal of about $86.98 \%$ and $94.57 \%$ for raw maize cob and maize cob activated carbon respectively. The dye removal efficiency was found to increase with increasing initial dye concentration from $10 \mathrm{mg} / \mathrm{L}$ to $100 \mathrm{mg} / \mathrm{L}$, and adsorption efficiency was found to be high at lower $\mathrm{pH}$. However, increase in the dosage of the adsorbents lead to the increase in the adsorption process. The equilibrium adsorption data were analyzed using four adsorption models: Langmuir, Freundlich, Temkin, and D-R. The results revealed that MO with raw maize cob and maize cob activated carbon fit well to Freundlich with $R^{2}$ value 0.977 and Temkin with $R^{2}$ value 0.990 respectively and mean adsorption energy calculated from $D-R$ shows it is physical adsorption and also values of enthalpy and Gibbs free energy proves that. Values of activation parameters such as free energy changes $(\Delta \mathrm{G})$, enthalpy change $(\Delta \mathrm{H})$ and entropy change $(\Delta \mathrm{S})$ were calculated using Van't Hoff equation. All $\Delta \mathrm{G}$ values were negative indicating that the adsorption was feasible and spontaneous. The result indicated that RMC and MCAC can be used for removal of MO from aqueous solution. The maize cob waste which is discarded as waste material was found to be effective adsorbent for the removal of Methyl orange dye from aqueous solution.
\end{abstract}

Keywords: Adsorbate; Adsorbent; Adsorption; Maize Cob; \% Removal.

\section{Introduction}

The discharge of dye bearing wastewater into natural stream or on land has created significant concern as the dye impact toxicity and impedes light penetration and thus upsets the biological activity [1]. The wastewater from the spent dye baths and dye rinsing unit shows unfixed dyes in it. Due to the low biodegradable nature of the dyes and also its color produces serious health problems to human beings and also other living organisms in the environment [2]. Therefore, removal of such dyes from wastewater is very important for the environment [3]. Activated carbon has been proven to be an effective and widely used adsorbent for the removal of a variety of organic and inorganic pollutants dissolved in aqueous solution [4]. Activated carbon (AC) are widely used in various fields such as purification and separation in many industrial processes including medicinal use, gas storage, pollutant, odor removal, gas separation, catalysis, pharmaceuticals, as electrode materials in electrochemical devices and in the wastewater treatment. Therefore, the demand for ACs is continuously increasing day by day. In practice, for the production of commercial ACs two primary sources such as coal and lignocellulosic materials are usually utilized. The composition of the lignocellulosic material regarding the cellulose, hemicelluloses and lignin content determines, to some extent, the porosity development of the produced ACs [5]. Agricultural by-products are renewable sources of raw materials for activated carbon production for the removal of color, dissolved metallic salts from aqueous solutions and also reduction of COD by adsorption [6]. The aim of this research is to study the adsorption properties of raw maize cob and activated carbon prepared from maize cob for the removal of Methyl orange which is a direct dye due to the presence of Azo group. Methyl orange (MO) is a commonly used an anionic monoazo dye in laboratory assays, textiles and other commercial products [7]. It is also a $\mathrm{pH}$ indicator frequently used in titrations because of its clear and distinct color change. It is toxic if ingested Studies have shown to be mutagen.

\section{Materials and Methods}

\subsection{Adsorbents Preparation}


The maize cob was obtained from kwanar karfi along Zaria road Kano, Nigeria, washed with tap water followed by distilled water to remove surface impurities and dried in an oven at $105^{\circ} \mathrm{C}$ for 3 hours. The dried maize cob (corn cob) was crushed using mortar and pestle and then divided in to two (2) portions, first portion was pulverized using blender and sieved using 425 micrometer, the powder was kept in tightly closed container for application and second portion for activated carbon.

\subsection{Preparation of Maize Cob Activated Carbon}

The method employed by Adebayo et al, [8] was adopted but with little modification in temperature for the preparation of maize cob activated carbon in which small portion was put into different pre-weighed crucibles and then introduced into furnace at a temperature of $500{ }^{\circ} \mathrm{C}$ for 20 minutes, the pyrolysed sample was allowed to cool and then activated with $\mathrm{H}_{3} \mathrm{PO}_{4}$. The char sample was mixed with $75 \%$ concentrated phosphoric acid in a beaker. The slurry was evaporated at $110{ }^{\circ} \mathrm{C}$ for 4 hours, and a dried mixture consisting of activated char and $\mathrm{H}_{3} \mathrm{PO}_{4}$ were obtained. This was washed several times till the $\mathrm{pH}$ reaches neutral. The sample was then purified by stirring in $250 \mathrm{~cm}^{3}$ of $0.1 \mathrm{M} \mathrm{HCl}$ for 1 hour. Finally the sample was washed severally to neutrality and then dries. The resulting activated carbon was kept tightly in a closed container for application.

\subsection{Batch Adsorption Experiment}

Adsorption studies of Methyl orange dye was performed. In this experiment $50 \mathrm{~cm}^{3}$ of dye solution in a $120 \mathrm{~cm}^{3}$ sample bottle of known concentration of desired time, temperature, dosage, and $\mathrm{pH}$. The bottle were agitated and the mixture was filtered and the filtrate was then centrifuged for 5 minutes at $4000 \mathrm{rpm}$ and the clear supernatant was used to determined the final concentration of the dye spectrophotometrically using UV-Visible spectrophotometer (model Hitach 2800) at a Predetermined $\lambda_{\max }$ of $463.65 \mathrm{~nm}$. The percentage of dye adsorbed and the amount adsorbed was calculated as [9]:

$\% \mathrm{R}=\frac{\mathrm{C}_{\mathrm{O}}-\mathrm{Ce}}{\mathrm{C}_{\mathrm{O}}} \mathrm{X} 100$

Where $\mathrm{C}_{0}$ is the initial concentration of the adsorbate $(\mathrm{mg} / \mathrm{L})$ and $\mathrm{C}_{\mathrm{e}}$ is the equilibrium concentration $(\mathrm{mg} / \mathrm{L})$.

$\mathrm{q}_{\mathrm{e}}=\frac{\left(\mathrm{C}_{\mathrm{o}}-\mathrm{C}_{\mathrm{e}}\right) \mathrm{V}}{\mathrm{W}}$

Where $\mathrm{w}(\mathrm{g})$ is the weight of adsorbent and $\mathrm{V}\left(\mathrm{cm}^{3}\right)$ is the volume of the adsorbate. The effects of various parameters on dye adsorption by RMC and MCAC were investigated such as contact time $(5-135 \mathrm{~min})$, adsorbent dosage $(0.5-4.0 \mathrm{~g})$ for RMC and $(0.1-2.0 \mathrm{~g})$ for MCAC. Initial dye concentration $(10-100 \mathrm{mg} / \mathrm{L})$, temperature $\left(25-45^{\circ} \mathrm{C}\right)$ and $\mathrm{pH}(2-12)[10]$.

\section{Results and Discussion}

\subsection{Characterization of Adsorbents (SEM and FTIR)}

The surface structure of adsorbents was analyzed by scanning electronic microscopy (SEM). It is clear that the adsorbent RMC revealed a smooth surface with irregularly space pores. The system has an irregular network but could likely provide favored adsorption site. Similarly SEM micrograph of MCAC showed that the adsorbents surface was irregular, rough and porous, indicating the possibility of its good adsorption properties. After dye adsorption, a significant change is observed in the structure of the adsorbents. The adsorbents appear to have a rough surface and pores containing new shiny particles after adsorption. (Fig 1a - 1d)

(A)

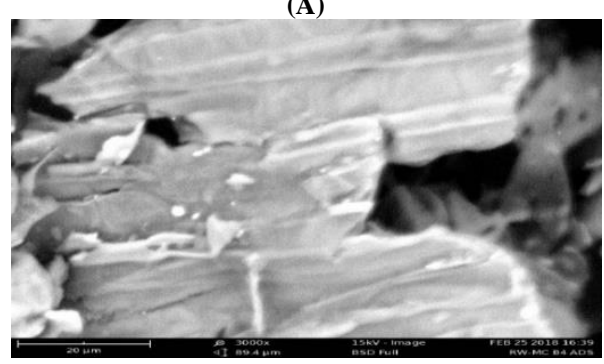

(C)

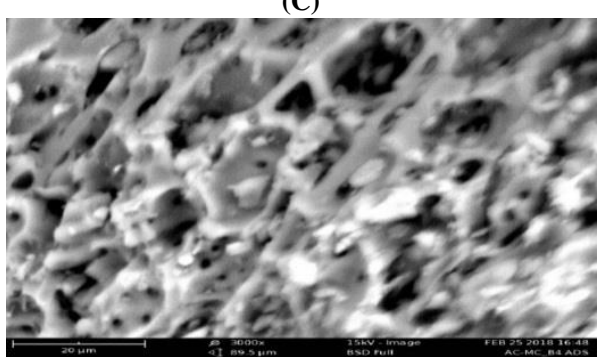

(B)

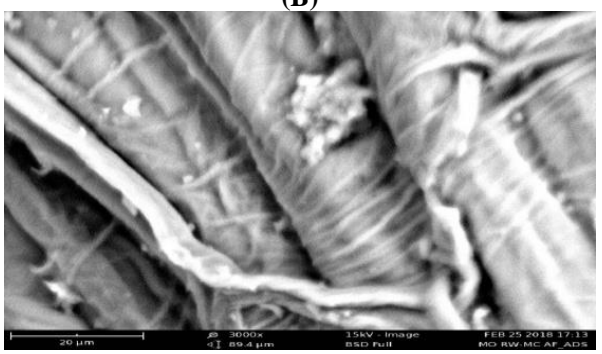

(D)

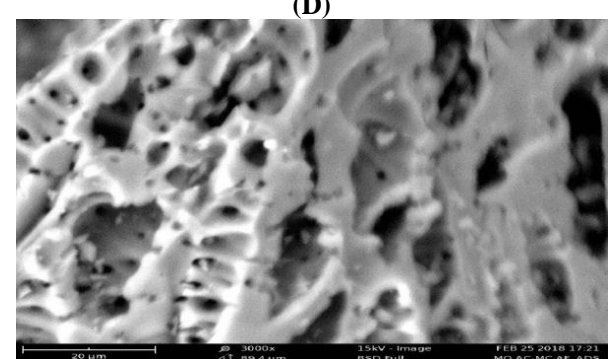

Fig. 1: A) SEM Image of Raw Maize Cob Before Adsorption. B) SEM Image of Raw Maize Cob After Adsorption. D) SEM Image of Maize Cob Activated Carbon After Adsorption. C) SEM Image of Maize Cob Activated Carbon Before Adsorption.

The FTIR spectroscopy method was used to obtained information about the nature of the functional groups responsible for the biosorption of the metal ions on the binding sites of the adsorbent [11]. The functional groups on the surface of RMC demonstrated the existence 
of $\mathrm{N}-\mathrm{H}$ stretching around $3287 \mathrm{~cm}^{-1}$ which shifted to $3335 \mathrm{~cm}^{-1}$, after adsorption. The peak around $2922 \mathrm{~cm}^{-1}$ signifies a finger print of $\mathrm{O}-\mathrm{H}$ bending which shifted to $2926 \mathrm{~cm}^{-1}$ and peaks at $1023 \mathrm{~cm}^{-1}$, and $2129 \mathrm{~cm}^{-1}$ indicated the presence of $\mathrm{C}-\mathrm{N}$ group and $\mathrm{C} \equiv \mathrm{C}$ group which shifted to other band. For MCAC, $\mathrm{O}-\mathrm{H}$ stretching around $3295 \mathrm{~cm}^{-1}$ before adsorption process, shifted to $3325 \mathrm{~cm}^{-1}$, after adsorption. The peaks around $1015 \mathrm{~cm}^{-1}, 2327 \mathrm{~cm}^{-1}$, and $1160 \mathrm{~cm}^{-1}$, are finger prints of $\mathrm{C}-\mathrm{O}$ stretching, $\mathrm{P}-\mathrm{H}$ bending and $\mathrm{C}-\mathrm{N}$ group respectively which later shifted to other bands after adsorption of MO.

(A)

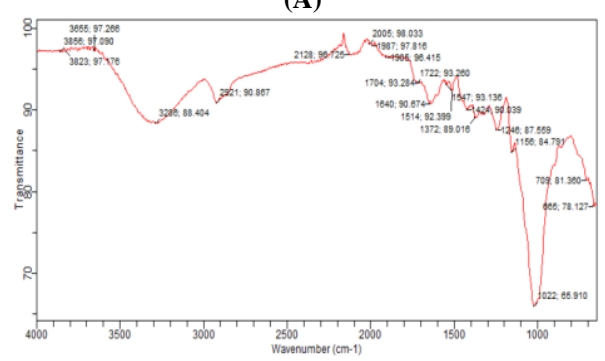

(C)

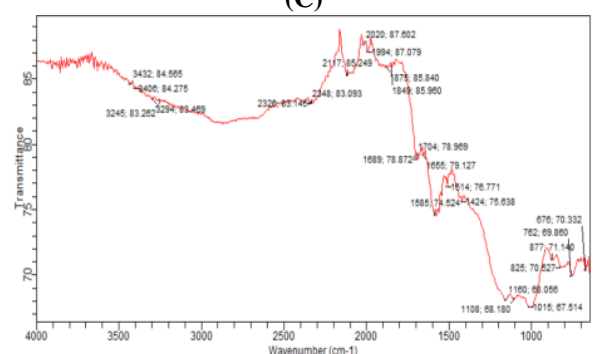

(B)

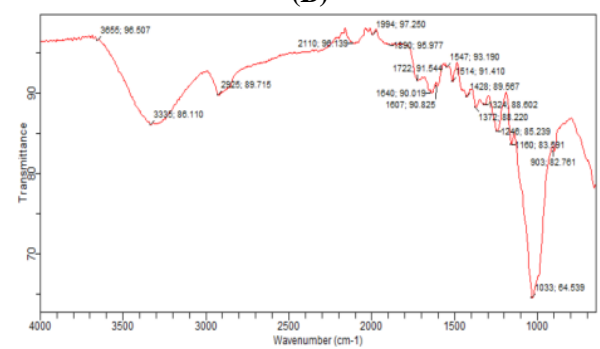

(D)

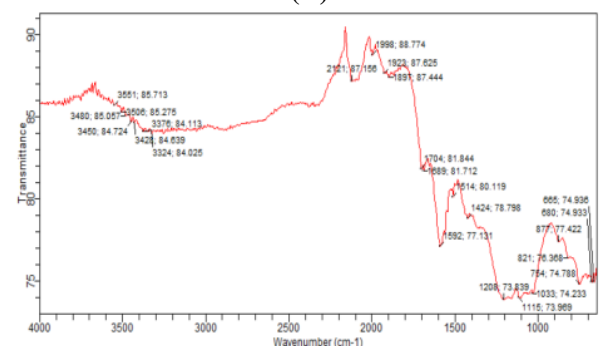

Fig. 2: A) FT-IR of RMC Before Adsorption. B) FT-IR of RMC After Adsorption. C) FT-IR Spectra of MCAC Before Adsorption. D) FT-IR of MCAC After Adsorption.

\subsection{Effect of Contact Time}

The contact time was evaluated as one of the important parameters affecting the adsorption efficiency. This parameter was examined by varying the time $(5,10,15,20,25,35,45,55,65,80,95,110,125$ and $135 \mathrm{~min})$ at a fixed agitation $(200 \mathrm{rpm})$, temperature $29{ }^{\circ} \mathrm{C}$, and dosage 0.5 and 0.2 for RMC and MCAC respectively. Figure 3 shows the effect of contact time on $\%$ removal of the dye. With increased agitation, the external mass transfer coefficient increases resulting in higher adsorption of the dye molecule. In this process, the dye molecules have to first encounter the boundary layer effect, then adsorption from the surface and finally, diffusion into the porous structure of the adsorbent [12-14]. The sorption rate was rapidly increased at the beginning of the adsorption process. Then, the adsorption was continued at a slower rate and finally reached saturation during 125 and $110 \mathrm{~min}$ for raw maize cob (RMC) and maize cob activated carbon (MCAC), respectively

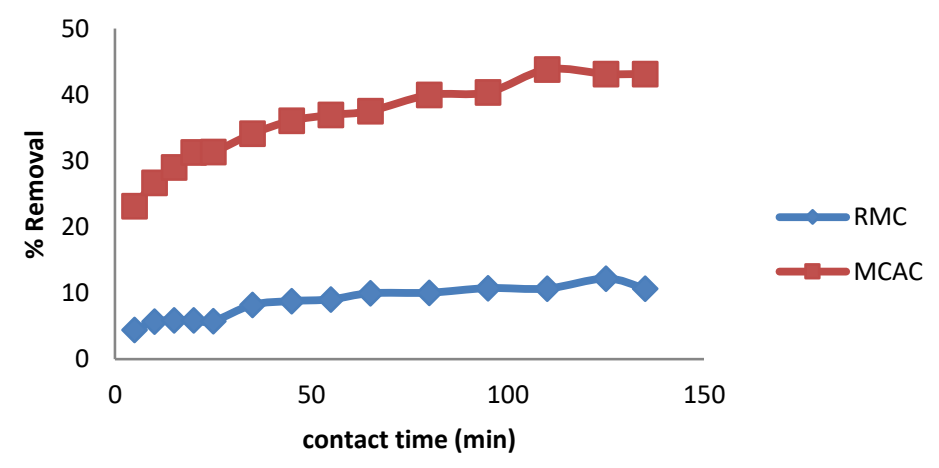

Fig. 3: Effect of Contact Time on the Removal of MO with MCAC and RMC.

\subsection{Effect of Adsorbent Dosage}

The percentage removal increases with increase in adsorbent dose. At equilibrium time (125 and $110 \mathrm{~min}$ ) increase in the dosage of RMC and MCAC from $0.5 \mathrm{~g}$ to $4.0 \mathrm{~g}$ and $0.1 \mathrm{~g}$ to $2.0 \mathrm{~g}$ respectively leads to significant increase in the removal efficiency of the dye from 5 $39 \%$ and $25-92 \%$ respectively. The increase in percentage removal was due to the increases of the available adsorption sites [15]. 


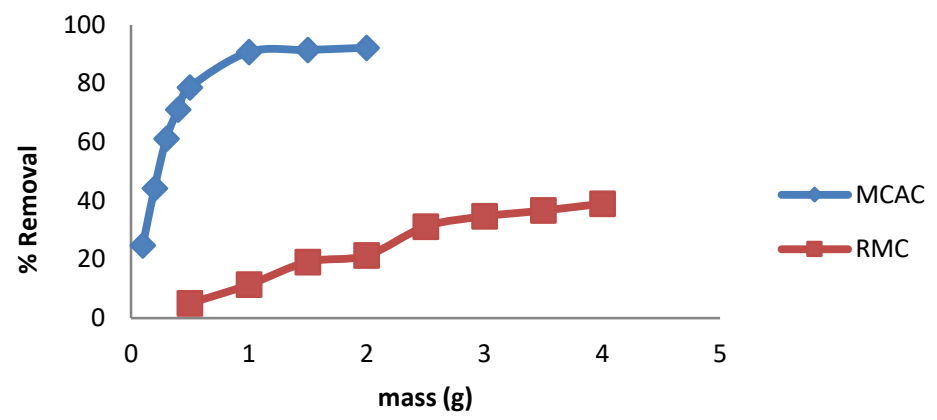

Fig. 4: Effect of Dosage on Removal of MO with RMC and MCAC.

\subsection{Effects of Initial Dye Concentration}

Initial dye concentration played important role on the sorption process by raw maize cob and maize cob activated carbon. The dye concentration were increased which later reach saturation at $100 \mathrm{mg} / \mathrm{L}$.

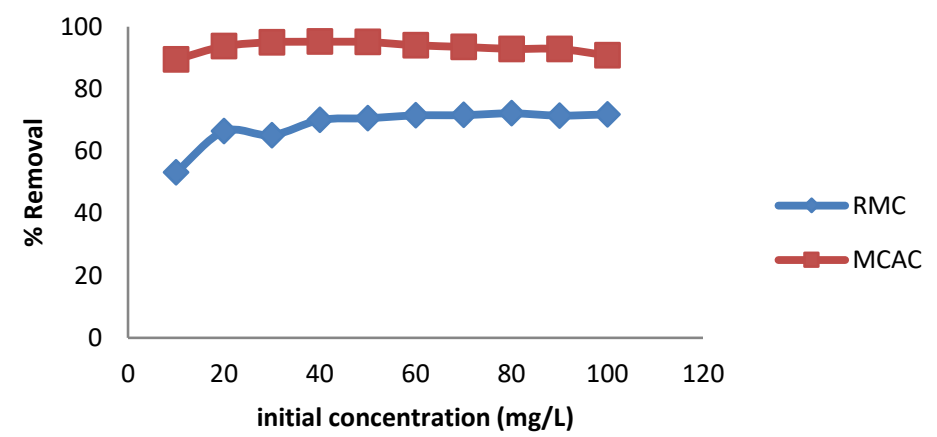

Fig. 5: Effect of Concentratio on Removal of MO with RMC and MCAC.

\subsection{Effects of Temperature}

Figures 6 shows that MO with MCAC was slightly increased with increase in temperature from 92.75 to $95.43 \%$, with increase of the solution temperature from 298 to $318 \mathrm{~K}$. It may be that the physical bonding between dye molecules and the active sites of the adsorbent weakened as temperature increased, whereas, the solubility of dyes increased thus enhancing the interaction forces between the solute and the solvent [16]. For MO with RMC the percentage removal decreases from 74.68 to $61.09 \%$ with increase in temperature from 298 to $318 \mathrm{~K}$. The variation in the removal may be as a result of the enhanced escaping tendency of pollutant species with increasing temperatures [17].

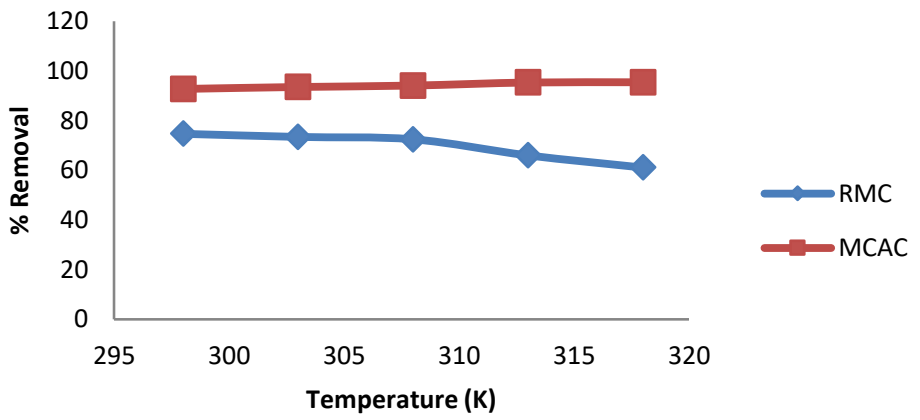

Fig. 6: Effect of Temperature on Removal of MO with RMC and MCAC.

\subsection{Effect of pH}

Effect of initial $\mathrm{pH}$ values from 2 to 12 on sorption process is given on Fig 7. At lower $\mathrm{pH}$, increased percentage removal was observed and at higher $\mathrm{pH}$ percentage removal decreased for both adsorbents. The acidic medium is favorable for the adsorption process of $\mathrm{MO}$. High adsorption capacity of dye at low $\mathrm{pH}$ indicates that, the surfaces of RMC and MCAC seem to be acidic which increase the protonation at their surfaces due to neutralization of negative charges, resulting in easier diffusion. This provides more active surface of the adsorbents and result into more adsorption at their surfaces. On increasing $\mathrm{pH}$, deprotonation takes place, which decreases the diffusion and adsorption [18-20]. 


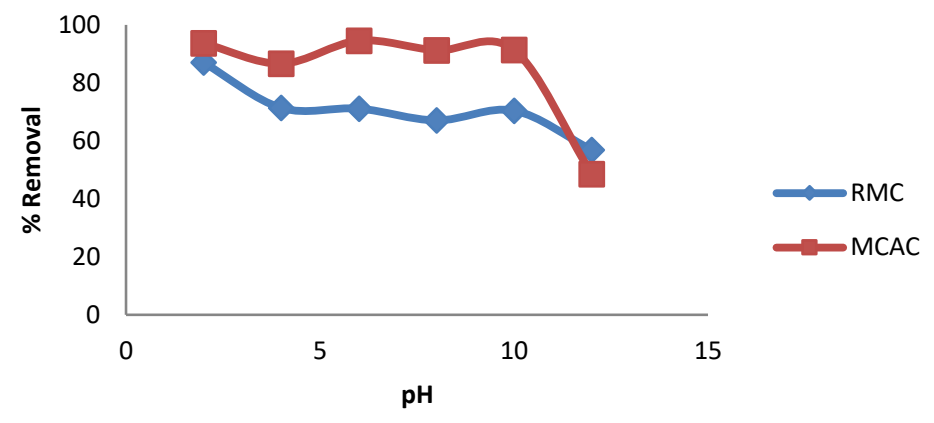

Fig. 7: Effect of pH on Removal of MO with RMC and MCAC.

\section{Adsorption Isotherms}

It used to show how the adsorption molecules distribute between the solid phase and liquid phase at adsorption equilibrium state [21]. In this work the equilibrium data were modeled using Langmuir, Freundlich, Temkin and D-R isotherms. Result indicated that the adsorption of MO fit with Freundlich and Dubinin Radushkevich isotherms with RMC and MCAC respectively by comparing high correlation coefficient as shown in table 1.

\subsection{Langmuir Isotherm}

The Langmuir isotherm theory assumes monolayer coverage of adsorbate over a homogeneous adsorbent surface. A basic assumption is that sorption takes place at specific homogeneous sites within the adsorbent. Once a dye molecule occupies a site, no further adsorption can take place at that site $[4,22]$. The linearized Langmuir isotherm is represented by equation 3.

$$
\frac{\mathrm{C}_{\mathrm{e}}}{\mathrm{q}_{\mathrm{e}}}=\frac{1}{\mathrm{~K}_{1} \mathrm{Q}_{\mathrm{m}}}+\frac{\mathrm{C}_{\mathrm{e}}}{\mathrm{Q}_{\mathrm{m}}}
$$

Where $\mathrm{C}_{\mathrm{e}}(\mathrm{mg} / \mathrm{l})$ is the dye equilibrium concentration and $\mathrm{q}_{\mathrm{e}}(\mathrm{mg} / \mathrm{g})$ is the amount of dye adsorbed per unit mass of adsorbent. $\mathrm{Q}_{\mathrm{m}}(\mathrm{mg} / \mathrm{g})$ is the Langmuir constants related to adsorption capacity and $\mathrm{K}_{\mathrm{L}}(\mathrm{L} / \mathrm{mg})$ is rate of adsorption. The values $\mathrm{K}_{\mathrm{L}}$ and $\mathrm{Q}_{\mathrm{m}}$ were calculated from the intercept and slope of linear plot of $\mathrm{C}_{\mathrm{e}} / \mathrm{q}_{\mathrm{e}} \mathrm{vs} \mathrm{C}_{\mathrm{e}}$. Applicability of Langmuir adsorption isotherm was verified by separation factor $\mathrm{R}_{\mathrm{L}}$, it defined whether adsorption is favourable or not.

$$
\mathrm{R}_{\mathrm{l}}=\frac{1}{1+\mathrm{K}_{1} \mathrm{C}_{\mathrm{o}}}
$$

Where $\mathrm{C}_{\mathrm{o}}(\mathrm{mg} / \mathrm{L})$ is the maximum adsorbate concentration in solution. The $\mathrm{R}_{\mathrm{L}}$ values between 0 and 1 show that the adsorption process is favorable [23]. As can be seen, adsorption process of MO onto RMC and MCAC surface was not favorable as defined by Langmuir isotherm model since linear regression value of Langmuir plot ware obtained as 0.502 and 0.113 respectively. Separation factor $\left(\mathrm{R}_{\mathrm{L}}\right)$ values were found to be not within the range of favorable In addition, Langmuir constant related to the adsorption energy $\mathrm{K}_{\mathrm{L}}$ and Maximum adsorption capacity $\mathrm{Q}_{\max }$ were both indicating non favorable process (Table 1).

\subsection{Freundlich Isotherm}

It is an empirical equation which indicates that the adsorption process takes place on a heterogeneous surface and adsorption capacity is related to the concentration of dye at equilibrium [24]. The Freundlich model is expressed in the following equation.

$\log \mathrm{q}_{\mathrm{e}}=\log \mathrm{K}_{\mathrm{f}}+\frac{1}{\mathrm{n}_{\mathrm{f}}} \log \mathrm{C}_{\mathrm{e}}$

Where $\mathrm{q}_{\mathrm{e}}$ is the amount of adsorbed dye at equilibrium $(\mathrm{mg} / \mathrm{g}) \mathrm{C}_{\mathrm{e}}$ is the equilibrium concentration of the adsorbate $(\mathrm{mg} / \mathrm{l}), \mathrm{K}_{\mathrm{f}}$ and $\mathrm{n}_{\mathrm{f}}$ are isotherm parameters indicative of adsorption capacity and adsorption intensity, respectively. The values of $\mathrm{K}_{\mathrm{f}}$ and $\mathrm{n}_{\mathrm{f}}$ were calculated from the intercept and slope of the plot of $\log \mathrm{q}_{\mathrm{e}}$ versus $\log \mathrm{C}_{\mathrm{e}}$. Generally, $\mathrm{n}_{\mathrm{f}}>1$ illustrates that adsorbate is favorably adsorbed on the adsorbent. The higher the number of $\mathrm{n}_{\mathrm{f}}$, the more favorable the adsorption and stronger the adsorption intensity [25]. As shown in the Table 1 . MO with RMC and MCAC have higher $\mathrm{R}^{2}$ value of 0.977 and 0.861 respectively, indicating that the adsorption fit with Freundlich and $\mathrm{n}_{\mathrm{F}}$ value being greater than one for MO with MCAC and less than with RMC suggest that adsorption is physical and chemical respectively.

\subsection{Temkin Isotherm}

Temkin isotherms provide information about the speciation of adsorption energy (heterogeneity) of the adsorbing surface. The isotherm assumes that the adsorption energy decreases linearly with surface coverage due to adsorbate/adsorbent interactions, thus heterogeneity of the adsorbing surfaces [26], [27]. The linear form of the Temkin model is expressed as follows:

$\mathrm{q}_{\mathrm{e}}=\mathrm{B}_{\mathrm{T}} \ln \mathrm{K}_{\mathrm{T}}+\mathrm{B}_{\mathrm{T}} \ln \mathrm{C}_{\mathrm{e}}$

$\mathrm{B}_{\mathrm{T}}=\frac{\mathrm{RT}}{\mathrm{b}_{\mathrm{T}}}$ 
Where $\mathrm{K}_{\mathrm{T}}$ is the Temkin equilibrium binding constant $(\mathrm{L} / \mathrm{mg})$ corresponding to maximum binding energy and constant $\mathrm{B}_{\mathrm{T}}$ is related to the heat of adsorption. The adsorption data were analyzed according to equation 6 . A plot of $\mathrm{q}_{\mathrm{e}}$ versus $\ln \mathrm{C}_{\mathrm{e}}$ yielded linear lines which enable the determination of the isotherm constants $\mathrm{K}_{\mathrm{T}}$ and $\mathrm{B}_{\mathrm{T}}$ from intercepts and slope respectively [24]. Temkin isotherm constant $\mathrm{b}_{\mathrm{T}}$ derived from $\mathrm{B}_{\mathrm{T}}$ constant refers to the heat of adsorption and is used to determine the adsorption characteristics, meaning whether it is a physical or chemical process [28]. Empirical results demonstrated that adsorption of dyes onto adsorbents surface showed a physical sorption character since Temkin isotherm constant $b_{T}$ was found to be lower than $8 \mathrm{~kJ} / \mathrm{mol} \mathrm{In}$ addition, good linear regression value of 0.944 and 0.990 with RMC and MCAC respectively indicates that adsorption process is fits closely with Temkin isotherm model.

\subsection{Dubinin-Radushkevich (D-R) Isotherm}

The Dubinin-Radushkevich D-R isotherm model is applied to determine the nature of dye adsorption by the adsorbent as chemical or physical [29]. The linear form of D-R isotherm can be shown as follows:

$$
\log q_{e}=\log q_{m}-\beta \varepsilon^{2}
$$

Where $\mathrm{q}_{\mathrm{m}}(\mathrm{mg} / \mathrm{g})$ is the theoretical saturation sorption capacity based on the isotherm, $\beta(\mathrm{kJ} / \mathrm{mol})$ is related to the mean adsorption energy, and $\varepsilon(\mathrm{J} / \mathrm{mol})$ is Polanyi potential which is equal to:

$$
\varepsilon=\mathrm{RT} \ln \left(1+1 / \mathrm{C}_{\mathrm{e}}\right)
$$

Where $\mathrm{R}(\mathrm{kJ} / \mathrm{mol} \mathrm{K})$ is the universal gas constant and $\mathrm{T}$ is temperature $(\mathrm{K}) . \mathrm{q}_{\mathrm{m}}$ and $\beta$ are obtained from the intercept and the slope of linear plot of $\log \mathrm{q}_{\mathrm{e}} \mathrm{vs} \varepsilon^{2}$, respectively. $\mathrm{E}(\mathrm{kJ} / \mathrm{mol})$ is the mean adsorption energy that is obtained from equation 10 :

$$
\mathrm{E}=\frac{1}{\sqrt{2 \beta}}
$$

The $\mathrm{E}$ values specified the type of adsorption process. The chemical ion exchange happened for the $\mathrm{E}$ value $8-16 \mathrm{~kJ} / \mathrm{mol}$. The physical and chemical adsorptions occurred when $\mathrm{E}<8$ and $\mathrm{E}>16 \mathrm{~kJ} / \mathrm{mol}$, respectively [28]. As shown in Table 1. The $\mathrm{E}$ values for the adsorption of MO with both adsorbents (RMC and MCAC) were in the range of $0-2 \mathrm{~kJ} / \mathrm{mol}$. These show that adsorption process by the adsorbent indicated physical process. In addition, good linear regression value of $\mathrm{R}^{2}$ greater than 0.90 showed favorable with $\mathrm{D}-\mathrm{R}$ isotherm

\begin{tabular}{|c|c|c|c|}
\hline Adsorption isotherm & Parameters & MO/RMC & MO/MCAC \\
\hline \multirow{4}{*}{ Langmuir } & $\mathrm{Q}_{\mathrm{M}}(\mathrm{mg} / \mathrm{g})$ & -0.917 & 9.091 \\
\hline & $\mathrm{R}_{\mathrm{L}}$ & -1.042 & 0.185 \\
\hline & $\mathrm{K}_{\mathrm{L}}(\mathrm{L} / \mathrm{mg})$ & -0.019 & 0.044 \\
\hline & $\mathrm{R}^{2}$ & 0.502 & 0.113 \\
\hline \multirow{3}{*}{ Freundlich } & $\mathrm{n}_{\mathrm{F}}$ & 0.724 & 1.092 \\
\hline & $\mathrm{K}_{\mathrm{F}}(\mathrm{mg} / \mathrm{g})$ & 0.009 & 0.391 \\
\hline & $\mathrm{R}^{2}$ & 0.977 & 0.861 \\
\hline \multirow{4}{*}{ Temkin } & $\mathrm{K}_{\mathrm{T}}(\mathrm{L} / \mathrm{mg})$ & 0.201 & 1.349 \\
\hline & $\mathrm{b}_{\mathrm{T}}(\mathrm{kJ} / \mathrm{mol})$ & 5.411 & 2.717 \\
\hline & $\mathrm{B}_{\mathrm{T}}(\mathrm{J} / \mathrm{mol})$ & 0.464 & 0.924 \\
\hline & $\mathrm{R}^{2}$ & 0.944 & 0.990 \\
\hline \multirow{3}{*}{$\mathrm{D}-\mathrm{R}$} & $\mathrm{Q}_{\mathrm{M}}(\mathrm{mg} / \mathrm{g})$ & 0.692 & 2.158 \\
\hline & $\mathrm{B}\left(\mathrm{mol}^{2} / \mathrm{kJ}^{2}\right)$ & 4.673 & 0.329 \\
\hline & $\mathrm{E}(\mathrm{kJ} / \mathrm{mol})$ & 0.327 & 1.233 \\
\hline
\end{tabular}
model.

Table 1: Langmuir, Freundlich, Temkin and D-R Isotherm Parameters for the Adsorption of MO onto Raw Maize Cob and Maize Cob Activated Carbon

\subsection{Adsorption Thermodynamics}

In order to evaluate the sorption process whether it is spontaneous process or not and exothermic or endothermic, thermodynamic parameters such as Gibbs free energy, adsorption enthalpy, and entropy were used and determined by equations below.

$$
\begin{aligned}
& \Delta \mathrm{G}=\Delta \mathrm{H}-\mathrm{T} \Delta \mathrm{S} \\
& \Delta \mathrm{G}=-\mathrm{RT} \ln \mathrm{K}_{\mathrm{c}} \\
& \mathrm{K}_{\mathrm{c}}=\frac{\mathrm{Q}_{\mathrm{e}}}{\mathrm{C}_{\mathrm{e}}} \\
& \ln \mathrm{K}_{\mathrm{c}}=\frac{\Delta \mathrm{S}}{\mathrm{R}}-\frac{\Delta \mathrm{H}}{\mathrm{RT}}
\end{aligned}
$$

Thermodynamics properties of the removal process are presented in Table 2, from the table it shows that the process was spontaneous for both adsorbents since $\Delta G$ values were negative. The negative $\Delta H$ value and positive $\Delta H$ indicated exothermic and endothermic process with RMC and MCAC respectively. Negative $\Delta \mathrm{s}$ value for MO with RMC shows decreased in randomness at the adsorbent-solution interface during the adsorption and Positive $\Delta \mathrm{s}$ value for MO with MCAC indicated spontaneous process. 
Table 2: Thermodynamic Parameters for Adsorption of MO on Raw Maize Cob and Maize Cob Activated Carbon

\begin{tabular}{|c|c|c|c|c|c|}
\hline \multirow[b]{2}{*}{ Dyes } & \multicolumn{3}{|c|}{ Raw Maize Cob } & \multirow[b]{2}{*}{$\Delta \mathrm{H}(\mathrm{kJ} / \mathrm{mol})$} & \multirow[b]{2}{*}{$\Delta \mathrm{S}\left(\mathrm{kJmol}^{1} \mathrm{~K}^{1}\right)$} \\
\hline & Temperature & $\mathrm{K}_{\mathrm{C}}$ & $\Delta \mathrm{G}(\mathrm{kJ} / \mathrm{mol})$ & & \\
\hline \multirow{4}{*}{$\mathrm{RMC}$} & 298 & 2.949 & -3.106 & \multirow{4}{*}{-38.486} & \multirow{4}{*}{-0.119} \\
\hline & 303 & 2.762 & -2.512 & & \\
\hline & 313 & 1.941 & -1.325 & & \\
\hline & 318 & 1.570 & -0.731 & & \\
\hline \multirow{5}{*}{ MCAC } & 298 & 12.79 & -6.286 & \multirow{5}{*}{20.918} & \multirow{5}{*}{0.091} \\
\hline & 303 & 14.47 & -6.742 & & \\
\hline & 308 & 15.98 & -7.199 & & \\
\hline & 313 & 20.39 & -7.655 & & \\
\hline & 318 & 20.90 & -8.111 & & \\
\hline
\end{tabular}

\section{Conclusion}

The maize cob waste which is discarded as waste material was found to be effective adsorbent for the removal of Methyl orange dye from aqueous solution. The removal efficiencies vary with conditions such as dosage, concentration, temperature and $\mathrm{pH}$. Result showed that Methyl orange adsorption was found to reach equilibrium within 125 and 110 minutes with optimum percentage removal of about $86.98 \%$ and $94.57 \%$ for RMC and MCAC, respectively.

\section{References}

[1] Alwan, R. M., Kadhim, Q. A., Sahan, K. M., Ali, R. A., Mahdi, R. J., Kassim, N. A. and Jassim, A. N. (2015). Synthesis of Zinc Oxide Nanoparticles via Sol - Gel Route and Their Characterization. Nanoscience and Nanotechnology, 5(1): 1-6.

[2] Kumar, P. S., Sivaranjanee, R., Vinothini, U., Raghavi, M., Rajasekar, K. and Ramakrishnan, K. (2013). Adsorption of Dye onto Raw and Surface Modified Tamarind Seeds: Isotherms Process Design, Kinetics and Mechanism. Desalination and Water treatment, 52, pp 2620-2633 https://doi.org/10.1080/19443994.2013.792016.

[3] [Ahmad, M, A., Herawan, S. G. and Yusof, A. A. (2014). Effect of Activation Time on The Pinang Frond Based Activated Carbon for Remazol Brilliant Blue R Removal. Journal of Mechanical Engineering and Sciences (JMES), Volum 7, pp. $1085-1093$. https://doi.org/10.1155/2014/184265.

[4] Okoye, C. C., Okey-Onyesolu, C. F., Chime, D. C., Achike, C. C. (2018). Adsorptive Removal of Bromophenol Blue Dye from Aqueous Solution using Acid Activated Clay. International Journal of Scientific Research and Management (IJSRM), 06(03): 01-15. https://doi.org/10.18535/ijsrm/v6i3.ce01.

[5] Saygili, H., Guzel, F., and Onal, Y. (2015). Conversation of Grape Indusrial Processin Water to Activated Carbon Sorbent and its Performance in Cationic and Anionic Dyes Adsorption. Journal of Cleaner Production, xxx: 1-10. https://doi.org/10.1016/j.jclepro.2015.01.009.

[6] Gumel, S. M. and Ismail, S. (2014). Use of Activated Carbon Derived from Maize Cob and Mahogany Seed Shell for the Removal of Colour from Textile Effluent. ChemSearch Journal, 6(2): $55-61$.

[7] Belay, K. and Hayelom, A. (2014). Removal of Methyl Orange from Aqueous Solutions Using Thermally Treated Egg Shell (Locally Available and Low Cost Biosorbent). Chemistry and Materials Research, 6(7): 31-39.

[8] Adebayo, G. B., Adegoke, H. I., Jamiu, W., Balogun, B. B. and Jimoh, A. A. (2015). Adsorption of Mn (II) and Co (II) ions from aqueous solution using maize cob activated carbon: kinetics and thermodynamic studies. J. Appl.Sci.Environ.Manage, 19(4): 737-748. https://doi.org/10.4314/jasem.v19i4.22.

[9] Abechi, S, E., Gimba, C, E., Uzairu, A. and Dallatu, Y, A. (2013). Preparation and Characterization of Activated Carbon from Palm Kernel Shell by Chemical Activation. Research Journal of Chemical Science, 3(7):54-61.

[10] Bentahar, S., Dbik, A., El-khomar, M., El-messaoudi, N., Bakiz, B. and Lacherai, A. (2016). Study of the Removal of Congo Red by Local Natural Clay. Chemistry \& Chemical Engineering, Biotechnology, Food Industry, Scientific Sturdy and Research, 17(3): 295-307.

[11] Babarinde, N. A. A., and Babalola, J. O. (2010). The Biosorption of Pb (II) from Solution by Elephant Grass (Pennisetum purpureum): Kinetic, Equilibrium, and Thermodynamic Studies. The Pacific Journal of Science and Technology, 11(1): 622-630.

[12] Ibrahim, M. B., Haruna. M. A., and Ibrahim, A. M. (2012). Optimization of Crystal Violet Dye Removal from Aqueous Solution Using Agro Wastes. ChemSearch Journal, 3(1): $28-33$.

[13] Adegoke, K. A. and Bello, S. O. (2015). Dye sequestration using agricultural wastes as adsorbents. Journal of Water Resources and Industry, 12: 8-24. A. https://doi.org/10.1016/j.wri.2015.09.002.

[14] Hashemian, S., Salari, K., Salehifar, H. and Yazdi, Z. A. (2013). Removal of Azo Dyes (Violet B and Violet 5R) from Aqueous Solution Using New Activated Carbon Developed from Orange peel. journal of chemistry, 1-10. https://doi.org/10.1155/2013/283274.

[15] Prasad, A. L., and Santhi, T. (2012). Adsorption of Hazardous Cationic Dyes from Aqueous Solution onto Acacia nilotica Leaves as an EcoFriendly Adsorbent. Sustain. Environ. Res, 22(2): 113-122.

[16] Yao, Y., He, B., Xu, F. and Chen, X. (2011). Equilibrium and kinetic studies of methyl orange adsorption on multiwalled carbon nanotubes. Chem ical Engineering Journal, 170: 82-89. https://doi.org/10.1016/j.cej.2011.03.031.

[17] Haghdoost, G. and Aghaie, H. (2015). Application of Corncob as a Natural Adsorbent for the Removal of Mn (II) Ion from Aqueous Solutions and Thermodynamic. Indian Journal of Fundamental and Applied Life Sciences, 5(3): 615-621.

[18] Jayalakshmi, L., Devadoss, V., Ananthakumar, K. and Kanthimathi, G. (2014). Adsorption Efficiency of Natural Clay towards the Removal of Naphthol Green Dye from the Aqueous Solution: Equilibrium and Kinetic Studies. International Research Journal of Environment Sciences, 3(5): 21-26.

[19] Salman, T. A., Adnan, A. E. and Hameed, S. T. (2017). Biosorption of Anionic and Cationic Dyes from their Aqueous Solutions Using Iraqi Sawdust. International Journal of Emerging Technology and Advanced Engineering, 7(8): 387-397.

[20] El-Dars, F. M. S., Ibrahim, H. M., Farag, H. A. B., Abdelwahhab, M. Z. and Shalabi , M. E. H. (2016). Preparation, Characterization of Bentonite Carbon Composite and Design Application in Adsorption Of Bromothymol Blue Dye. Journal of Multidisciplinary Engineering Science and Technology (JMEST), 3(1): 3758-3765.

[21] Attia, A. A., Khedr, S. A., and Elkholy, S. A. (2010). Adsorption of Chromium Ion (VI) By Acid Activated Carbon, Brazilian. Journal of Chemical Engineering, 27(1): 183 - 193. https://doi.org/10.1590/S0104-66322010000100016.

[22] Garba, Z. N., Bello, I., Galadima, A. and Lawal, A. Y. (2015). Optimization of adsorption conditions using central composite design for the removal of copper (II) and lead (II) by defatted papaya seed. Karbala Internationa Journal of modern science, XX, 1-9. https://doi.org/10.1016/j.kijoms.2015.12.002. 
[23] Patil, S., Renukdas, S. and Patel, N. (2011). Removal of methylene blue, a basic dye from aqueous solutions by adsorption using teak tree (Tectona grandis) bark powder. International Journal of Environmental Sciences, 1(5): 0976 - 4402.

[24] Banerjee, S. and Chattopadhyaya, M. C. (2013). Adsorption Characteristic for the Removal of a Toxic Dye Tatrazine from Aqueous Solutions by a Low-Cost Agricultural By-product. Arabian Journal of Chemistry, 1878-5352.

[25] Iqbal, M. J. and Ashiq, M. N. (2010). Thermodynamics and Kinetics of Adsorption of Dyes from Aqueous Media onto Alumina. J. Chem.Soc.Pak, 32(4): 419-428.

[26] Zubairu, S. M. J., Uzairu, A., Iyun, J. F., Abechi, S. E. and Okunola, J. O. (2011). MethyleneBlue Adsorption from Glycerol Solution onto the Acicular Habit of $\alpha$-Goethite. Chemical Society of Ethiopia, 25(1): 25-35. https://doi.org/10.4314/bcse.v25i1.63357.

[27] Piccin, J. S., Dotto, G. L. and Pinto, L. A. A. (2011). Adsorption Isotherms and Thermochemical Data of FD\&C Red N 40 Binding by Chitosan, Brazilian Journal of Chemical Engineering, 28(2): 295 - 304. https://doi.org/10.1590/S0104-66322011000200014.

[28] Akalin, H. A., Hicsonmez, U. and Yilma, H. (2017). Removal of cesium from Aqueous Solution by Adsorption onto Sivasyildizeli (Turkiye) Vermiculite: Equilibrium, Kinetic and Thermodynamic sturdies. Journal of Turkish General Sturdies, 5(1): 85-116. https://doi.org/10.18596/jotcsa.317771.

[29] Nourmoradi, H., Ghiasvand, A, R. and Otlagh, Z. N. (2015). Removal of Methylene Blue and Acid Orange 7 from Aqueous Solutions by Activated Carbon Coated with Zinc Oxide ( $\mathrm{ZnO})$ Nanoparticles: Equilibrium, Kinetic, and Thermodynamic Sturdy. Desalination and water treatment, 55, pp 252-262. https://doi.org/10.1080/19443994.2014.914449. 